This case was six months and a half advanced. The child was living, and died in 28 hours.

We have means now within our power, with which in former years we were unacquainted,-the ergot for instance; but perhaps there may have been unfortunate results from incautious use of it; and very satisfactory effects in many cases may, I think, be obtained more safely from opium. Mrs. O., in December last, is an example.

June 25, $185 \mathrm{I}$.

\section{A CASE OF}

NON-UNION OF FRACTURE OF BOTH BONES OF THE LEG, OF EIGHTEEN WEEKS' STANDING, SUCCESSFULLY TREATED BY MERCURY.

By R. TIIURSfield, Esq., M.R.C.S., Broseley. SENIOR-BURGEON TO IRONBRIDGE DISPEXSARY.

IN the month of August, 1847, I was asked to see an old patient of mine, aged 42 , who had twice suffered severely from acute rheumatism. I learnt from her that about eighteen weeks before, she had, on returning from an evening visit to her sister, slipped in crossing a rough road, and fractured both bones of the leg just above the ankle. She was not far from her sister's house, and a surgeon was soon in attendance. Her leg was placed on a pillow and the usual means employed; but in about six weeks after the accident it was ascertained that no bony union had taken place. Upon further advice starch bandages were applied; but no benefit resulted. On examining the leg I found it greatly swollen, shorter by an inch at least than the other, with a good deal of deformity, greatly increased by any attempt at standing upon it, and the least motion at the point of fracture. She had greatly increased in bulk during the confinement she had undergone, but considered herself in good health.

I was a good deal puzzled what plan to pursue with the best chance of successfully relieving her, for I had never had to treat such a case before, and the uncertain results in the experience of others were anything but encouraging. In thinking over the case I remembered that the late Mr. Tyrrell had said mercury in his hands had proved at least as efficacious as any other plan he had tried; and I made up my mind to use it, because the peculiarly irritable state of the patient put sawing off the ends of the bone, seton, or any other surgical means quite out of the question, and most others seemed to have been fairly tried. I therefore procured two very strong gutta percha splints, which reached from rather above the knee to the bottom of the foot, and having, on the 18th, soaked them in boiling water, I made a complete cast of the leg by passing a tight roller over them and allowing them to cool. Having brought the ends of the bones as nearly into apposition as I could and covered the parts with mercurial ointment, \&c., after the plan recommended by Mr. John Scott, I applied the splint, and bound all together with a long elastic bandage. I confined her to bed, and tied the leg on a pillow, giving her five grains of blue pill night and morning. No perceptible effect from the mercury took place until she had taken sixteen pills, when suddenly violent ptyalism set in, which lasted a fortnight. On the 7 th of October the bandages, \&c., were removed, as they had become loose from the reduced size of the leg, and a great improvement was found to have taken place The leg was longer, the deformity less, and the motion at the fracture scarcely perceptible. Greatly encouraged by such a state of things, I renewed the applications exactly as at first, and allowed her to use a sofa during the day. In about three weeks I again tightened the roller, and in another month removed everything from the leg, and found the fracture perfectly united and firm. For a month after this time she had the leg well rubbed night and morning with camphorated oil, to get rid of the remaining œdema, wearing a roller and one splint during the day, to protect the leg if she should chance to slip in walking. In six months she could walk well two or three miles, and is now as active as most women of her age, the broken leg being as useful as the other.

\section{CASES IN PRIVATE PRACTICE.}

\section{By JAMES KITSELL, Esq., Droitwich.}

Read at the Nineteenth Anniversary Meeting, held at Brighton,August, 1851.

Case I.-Case of Retention of Urine, with False Passage, and Paralysis of Bladder.

Is March, 1850, I was requested to attend J. P., a farmer of independent means, who had laboured under retention of urine at intervals for nearly a week. On my arrival, the medical man in attendance, " although not qualified," had made numerous attempts, unsuccessfully, to introduce the catheter; a medical gentleman from Birmingham having also visited the case twice, and succeeded in introducing the catheter, though not without great loss of blood, owing in some measure to the unskilful use of the instrument, before his arrival, and the formation of a false passage, which, considering the age of the patient, $(69$,$) who was of impaired$ constitution, rendered the case very serious. On my arrival I learnt from the patient that he had long been subject to dribbling of urine, frequent inc'ination to void it, and other symptoms indicative, at lis period of life, of prostatic enlargement, of which I satisfied myself on examination per rectum. On introducing the catheter it readily entered the false passages, and no little manœuvring was required to conduct it into the bladder. The instrument being of No. 5 size, passed with difficulty through the constricted prostatic portion if the "rethra, when about two pints of urinn were 